\title{
Do new records of macrofungi indicate warming of their habitats in terrestrial Antarctic ecosystems?
}

\author{
Götz Palfner ${ }^{1}$, Josefa Binimelis-Salazar ${ }^{1}$, Sandra Troncoso Alarcón ${ }^{1}$, \\ Gustavo Torres-Mellado ${ }^{1}$, Gloria Gallegos ${ }^{1}$, Fernando Peña-Cortés ${ }^{2}$, \\ Angélica Casanova-Katny ${ }^{3 *}$
}

${ }^{1}$ Laboratory of Mycology and Mycorrhiza, Faculty of Natural Sciences and Oceanography, Concepción University, Campus Concepción, Chile

${ }^{2}$ Laboratory of Spatial Planning, Environmental Sciences Department, Faculty of Natural Resources, Catholic University of Temuco, Chile

${ }^{3}$ Laboratory of Plant Ecophysiology, Faculty of Natural Resources, Catholic University of Teтuco, Campus Luis Rivas del Canto, Rudecindo Ortega \#03694, Temuco, Chile

\begin{abstract}
Relatively few macrofungi have been historically described from terrestrial environments of the Antarctic Peninsula and its associated archipelagos which are characterized by a moss-dominated vegetation, most of them preferentially or obligatorily associated with bryophytes. During the study of the influence of penguin rockeries to moss communities on the South Shetland Islands, the bryophilous basidiomycetes Rimbachia bryophila and Arrhenia cf. lilacinicolor were found for the first time on King George Island, growing on carpets of Sanionia uncinata. Other bryophilous fungi previously recorded in the same region are Arrhenia antarctica, Omphalina pyxidata and the rare Simocybe antarctica. The detection of the supposedly parasitic $R$. bryophila, together with other new observations of macrofungi on different hosts in the Antarctic bryoflora could indicate increased sexual reproduction. The likely increase of reproduction as an effect of warming on the terrestrial antarctic tundra should be proven by follow up field studies.
\end{abstract}

Key words: Basidiomycetes, bryophytes, antarctic fungi, parasitism, Antarctica

DOI: $10.5817 / \mathrm{CPR} 2020-2-21$

\footnotetext{
Received November 26, 2020, accepted December 30, 2020.

*Corresponding author: A. Casanova-Katny $<$ mcasanova@uct.cl $>$

Acknowledgements: Dra. Casanova-Katny acknowledges the logistic support of the Instituto Antartico Chileno (INACH) during the ECA 55 and 56, also the staff of the Spanish station Gabriel de Castilla during field work on Deception Island; funding was by ANIDFONDECYT1181745. Our special thanks to Dr. Egon Horak, Innsbruck University, Austria, for providing important information about antarctic fungi and to the two reviewers for improving our manuscript.
} 


\section{Introduction}

The first native macromycete reported from the maritime Antarctica, according to Singer (1956), was Omphalina antarctica Singer collected by F. Behn on Deception Island in 1952. Since then, the number of records of mushroom-forming basidiomycetes from natural habitats in the region has slowly but steadily increased (Horak 1982, Pegler et al. 1980). Owing to the vegetation which is dominated by cryptogams, most of these fungi are more or less exclusively associated with bryophytes. A problem for more extensive surveys of macrofungi in Antarctica is the limited window in time for field campaigns due to the climatic conditions and logistic restrictions. Nevertheless, the research group led by Dr. Casanova Katny, senior author of this article, has been able to join a considerable number of collections of bryophilous mushrooms during field campaigns on different islands of the South Shetland Archipelago between 2008 and

\section{Material and Methods}

\section{Study site}

Fildes Peninsula $\left(62^{\circ} 12^{\prime} 6.56^{\prime \prime} \mathrm{S}, 58^{\circ} 58^{\prime}\right.$ $16.61 " \mathrm{~W}$ ), our main collection site, is the main ice-free area of King George Island (KGI), forming part of the South Shetland Archipelago on the western coast of the Antarctic Peninsula (WAP) (Fig. 2). This ice-free area has an extension of $28 \mathrm{~km}^{2}$, with $8 \mathrm{~km}$ long and a width that fluctuates between 1.5 and $4 \mathrm{~km}$. Geomorphological evidence accounts for the occurrence of paraglacial and periglacial processes, which began $12 \mathrm{ka}$ before the present, with the removal of the ice sheet and subsequent occurrence of eustatic and isostatic processes. This has shaped the area that has been colonized by mosses and in particular by the genus Sanionia (González et al. 2019). The island presents a cold maritime
2020, particularly during the scientific expedition in 2019 and 2020 to maritime Antarctica, with forays on Deception Island and Fildes Peninsula on King George Island. Some of the inventoried macrofungi represent new records for the area, others extend the known diversity of bryophyte hosts and all of them contribute new spots on the map of higher fungi in Antarctica. We consider it important to publish this information in order to add to the baseline of local and regional fungal diversity, as climate change is strongly influencing biodiversity and interaction between organisms in the Antarctic. Considering the important roles of saprobic fungi in nutrient cycling and of fungal parasites in the balance of plant communities, changes in their richness, abundance and reproductive patterns of the mycobiota are supposed to impact the associated vegetation and thus to have an effect at the habitat and ecosystem level.

climate. The mean daily air temperature on Fildes Peninsula fluctuates between 0.6$1.5^{\circ} \mathrm{C}$ during the spring-summer season, with the lowest values during winter. The peninsula has relatively high rainfall, with 40-70 $\mathrm{mm}$ in the summer season, being overcast almost $70 \%$ of days (Carrasco and Gonzalez 2007). Deschampsia antarctica Desv. is the only vascular plant species in the area and terrestrial landscape (Torres-Mellado et al. 2011) is dominated by cryptogam communities. For the area, 109 lichen species (Andreyev 1989) and 40 moss species have been reported which represent $50 \%$ of the identified Antarctic mosses growing across the continent (Ochyra et al. 2008). Two species of Sanionia, S. georgicouncinata (Müll. Hal.) Ochyra \& 
Hedenäs and $S$. uncinata (Hedw.) Lowske grow on King George Island (Ochyra et al. 2008) where they cover large areas (Casanova-Katny and Cavieres 2012) (Fig. 1). $S$. uncinata is a pioneer species in watersaturated areas in depressions with stagnant or running water from snow banks or glaciers on nutrient rich areas visited by birds. Nine collections of macrofungi (Basidiomycota) mainly associated to cush-

\section{Collection and processing of samples}

Basidiomata encountered during opportunistic forays were documented in situ (photos, georeferences, field notes), carefully extracted with a pocket knife and taken to the field station covered in aluminium foil where they were dehydrated on a portable electric dryer for transport to the laboratory at Concepción University.

For microscopical analysis, air-dried specimens deposited at the fungal collection at Concepción University (CONC-F) ions of $S$. uncinata, were found on Fildes Peninsula, at Collins Bay, Juan Carlos Point and La Cruz Plateau. In addition to our collections on King George Island, three collections were found during the expedition on Robert Island and Deception Island during the study of penguin rockeries associated moss communities during 2019-2020, at La Descubierta Point and the area of Crater Lake.

were used. Small pieces of basidiomata were removed with a razor blade or fine forceps and soaked in a droplet of 5\% potassium hydroxide solution on a glass slide before being observed under a Leitz Dialux microscope (Leitz, Wetzlar, Germany) at $1000 \times$ magnification. Diagnostic attributes like spores and cystidia were measured and documented with a Nikon Coolpix 950 digital camera (Nikon, Tokyo, Japan) attached to the microscope.

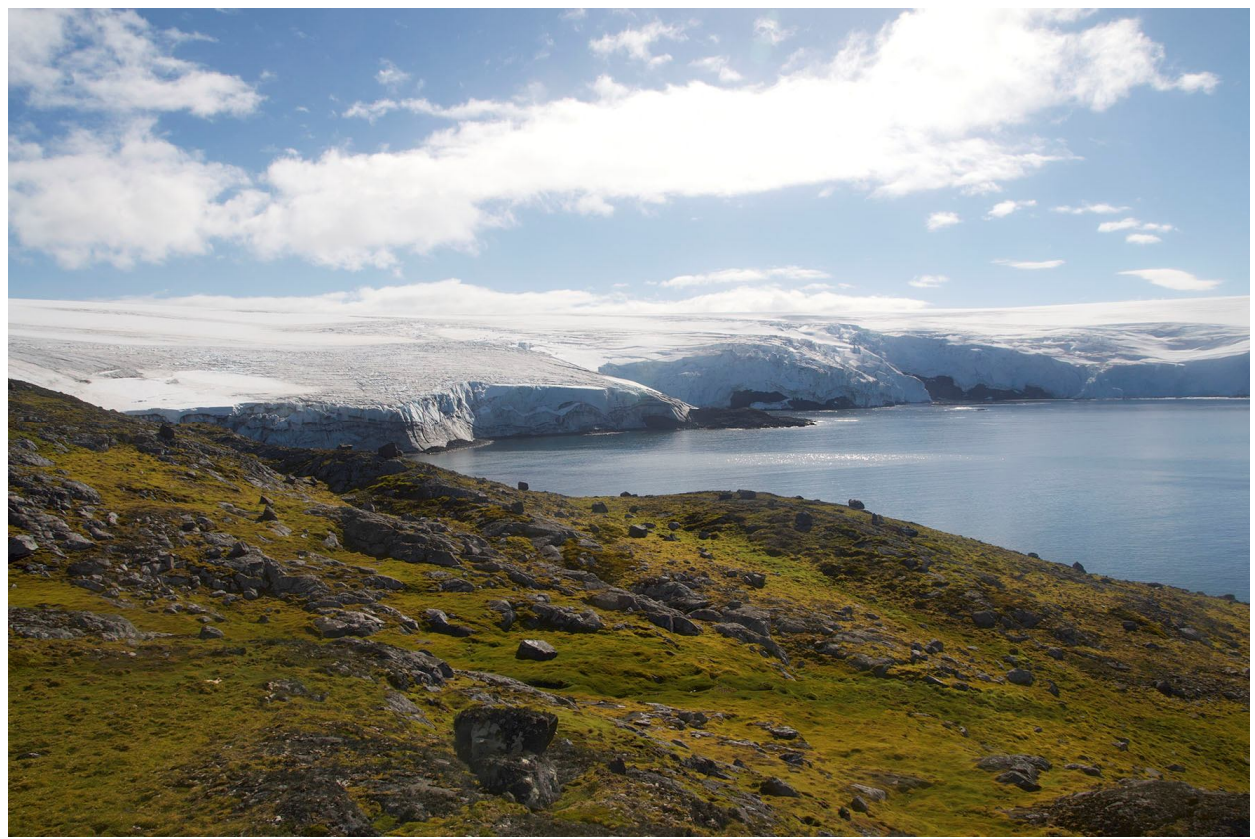

Fig. 1. View on Collins Bay, Fildes Peninsula, King George Island, maritime Antarctica (March 2019), with extensive moss carpets; one of the most favorable sites for viewings of macromycetes where several of our collection spots are located. 
To visualize microscopic details with low contrast, samples were stained with congo red solution. Spore measurements (minimum, average and maximum length and width; length-width quotient Q $1 / \mathrm{w}$ ) are based on values obtained from at least 10 randomly selected spores in lateral view. For species identification and retrieving information about their ecology and distribution, the following references were used: Elborne 2012, Guminska et al. 1994, Horak 1982, Høiland 1976, Gminder and Krieglsteiner 2001, Læssøe 2012, Pegler et al. 1980, Putzke and Pereira 1996, Putzke et al. 2012, Redhead 1984, Segedin 1994, Senn-Irlet and Moreau 2003, Singer 1956, Vizzini et al. 2012, among others. Current names and basionyms were assigned to species mostly according to Index Fungorum [1].

\section{Results}

We report 14 new records of bryophilous macromycetes (Agaricales, Basidiomycota) from the South Shetland Archipelago between 2008 and 2020, belonging to six species. Two of them, Rimbachia bryophila and Arrhenia cf. lilacinicolor, are first records for Antarctica. Taxonomic

descriptions are presented for five species, and a dichotomous identification key is provided for all well-documented agaricoid macromycetes reported so far from the archipelago. Locations of our findings are shown in Fig. 2.

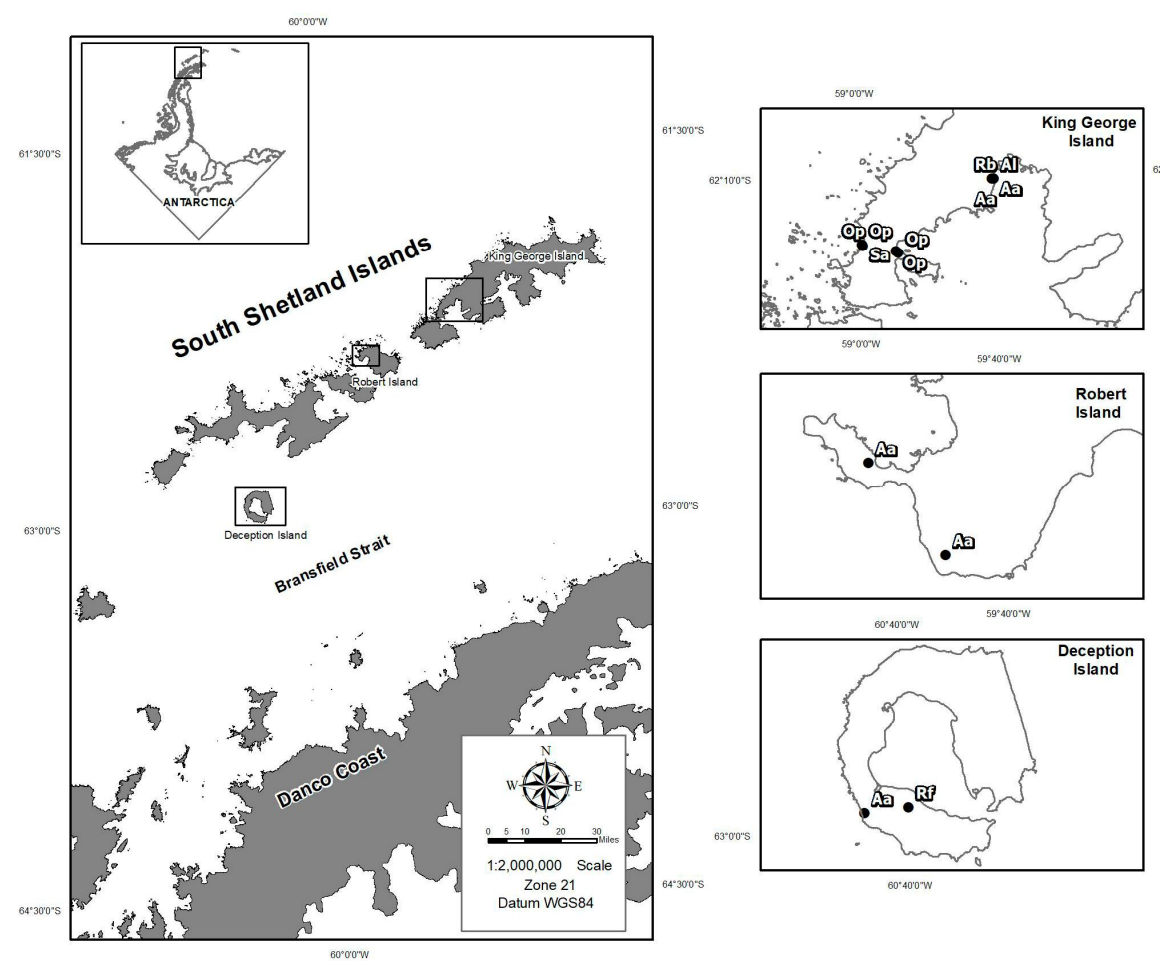

Fig. 2. Locations of macrofungi records from South Shetland Archipelago, maritime Antarctica, retrieved by the research group of Dr. Casanova Katny between 2008 and 2020.

Legend: $\mathrm{Rb}$ - Rimbachia bryophila, Sa - Simocybe antarctica, Aa - Arrhenia antarctica, $\mathrm{Al}$ - Arrhenia cf. lilacinicolor, Op - Omphalina pyxidata, Rf - Rickenella fibula. 


\section{Taxonomy}

Rimbachia bryophila (Pers.) Redhead, Can. J. Bot. 62(5): 878 (1984)

Basionym: Agaricus bryophilus Pers. 1795.

Systematic context: Tricholomataceae, Agaricales, Agaricomycotina, Basidiomycota.

Description: Basidiomata gregarious, cup-shaped, conchate or flabellate, sessile, 1-5 mm in diameter, pure white to creamy white, upper surface pubescent, hymenium smooth or slightly wrinkled in juvenile stage, at maturity with prominent lamella-like veins (Fig. 3a, b); spores 5.7-6.9-8.5 × 5-5.6-7.2 $\mu \mathrm{m}$, subglobose (Q 1/w $=1.1-1.3$ ), hyaline, inamyloid, with distinct hilar appendix (Fig. 3c); basidia clavate, hyaline, tetrasporic; cystidia not observed; hyphal septa with clamp-connections.
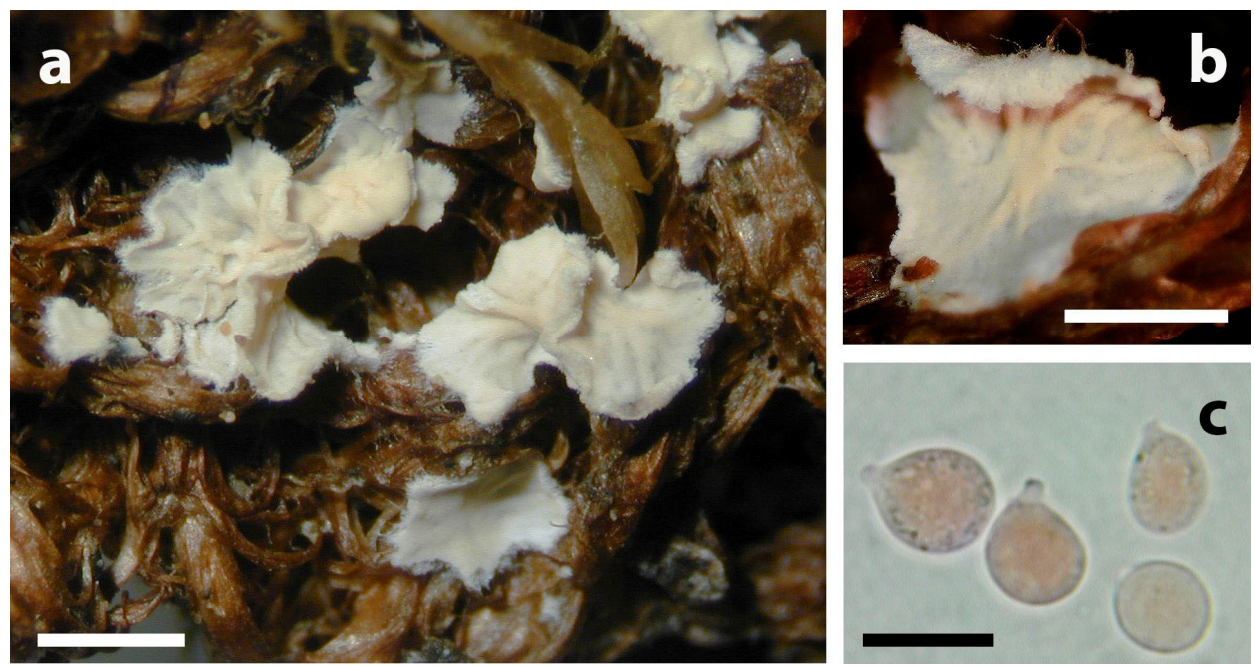

Fig. 3. Rimbachia bryophila (CONC-F0676) from Antarctica, King George Island (dehydrated collection): a) basidiomata on Sanionia uncinata (bar $=1 \mathrm{~mm}$ ); b) enlarged view on basidioma showing hymenium with lamella-like folds and villose pileal surface (bar $=1 \mathrm{~mm}$ ); c) basidiospores stained with congo red (bar $=10 \mu \mathrm{m}$ ).

Habitat and substrate: In Antarctic tundra on gametophytes of Saniona uncinata (Bryophyta), supposedly parasitic.

Examined material: Maritime Antarctica, South Shetland Archipelago, King George Island, Collins Bay, S 62 10' 09.6" W 58 51' 14.0", 11-I-2009, leg. A. CasanovaKatny, det. G. Palfner, CONC-F0676.

Distribution: rare but widely distributed in temperate, boreal, montane and polar habitats on both hemispheres, always associated to pleurocarpic mosses (Hausknecht and Klofac 2011, Kaya et al. 2013, Læssøe 2012, Redhead 1997, Segedin 1994, Senn-Irlet and Moreau 2003, Svane and Alstrum 2004).

Comments: This is the first record of the species for Antarctica; with respect to adjacent regions, records exist from New Zealand (Segedin 1994) but to our knowledge not from Southern South America; only the closely related $R$. arachnoidea subsp. bispora (Singer) Redhead (1984: 879) has been recorded recently from Chile (Diban 2019). 
Although average spore size of our collection coincides with relevant references (e.g. Redhead 1997), we found a major number of notably larger spores, reaching up to $8.5 \mu \mathrm{m}$ in length. With respect to the suggested parasitism of $R$. bryophila, we observed mycelial growth on the surface of green thalli of $S$. uncinata in close vicinity of the basidiomata but not appresoria, haustoria or other parasitic structures inside the host tissue.

Simocybe antarctica Pegler, Spooner y Lewis-Smith, Kew Bull. 35(3): 552 (1980) Systematic context: Crepidotaceae, Agaricales, Agaricomycotina, Basidiomycota.

Description: Basidiomata gregarious, spathulate to reniform, substipitate; pileus applanate with an incurved margin when young, 2-5 mm diam., brownish, hygrophanous, turning pale cream-fawn, velutinous; hymenium lamellate, lamellae distant, adnexed to adnate, concolorous with pileus; stipe reduced, excentric to lateral, more rarely central, whitish to pale yellowish (Fig. 4a); spores 7-7.6-8.5 $\times$ 5.7-6.7-7.2 $\mu \mathrm{m}$, subglobose to ovoid (Q 1/w = 1.1-1.3), with suprahilar depression, brown, smooth, thick-walled (Fig. 4b); basidia clavate, tetrasporic; cheilocystidia slender, cylindric to lageniform, subcapitate or capitate (Fig. 4c), pleurocystidia not observed; hyphal septa with clampconnections.
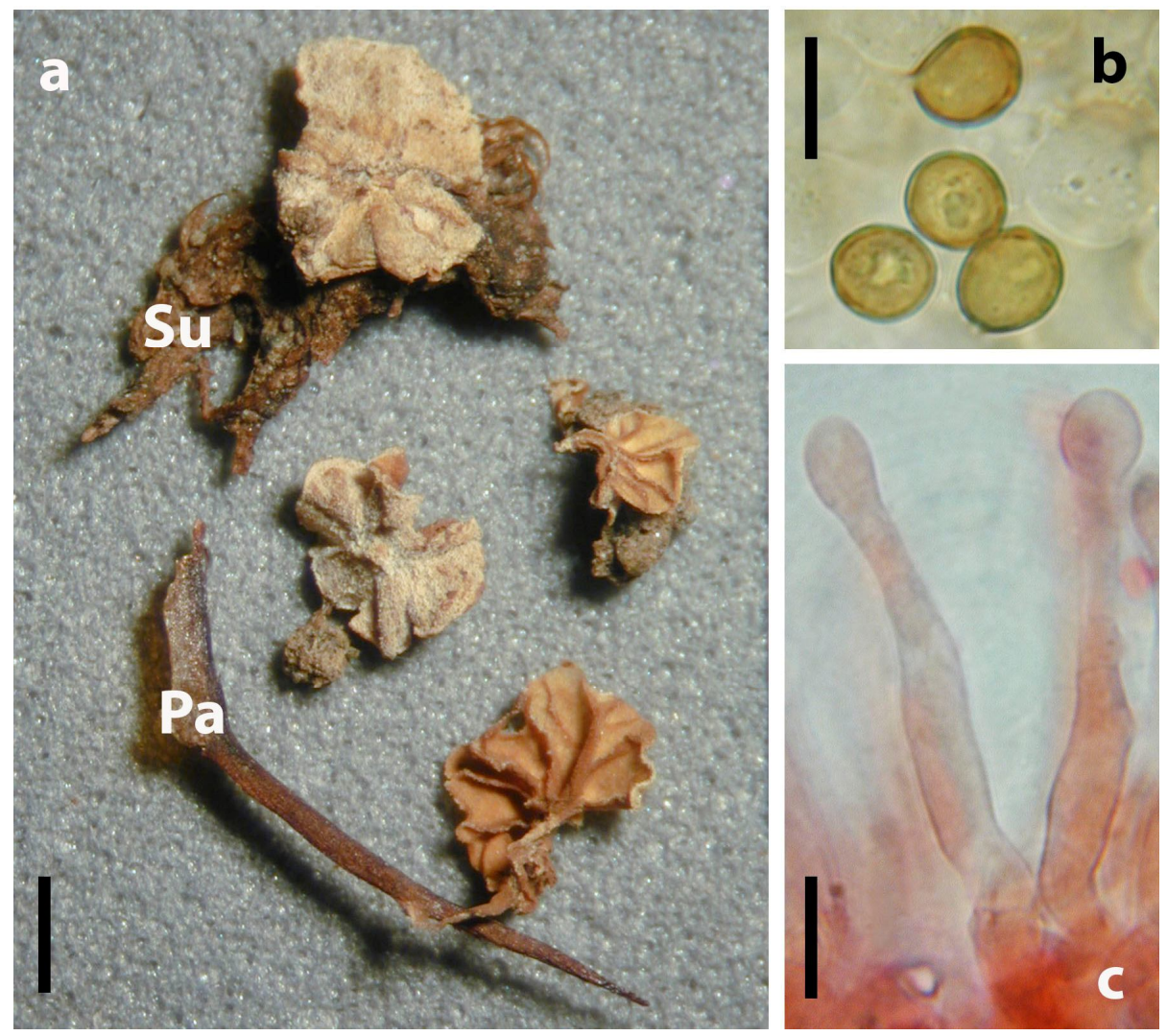

Fig. 4. Simocybe antarctica (CONC-F0349) from Antarctica, King George Island (dehydrated collection): a) basidiomata on remnants of Sanionia uncinata ( $\mathrm{Su}$ ) and Polytrichastrum alpinum (Pa) $(\mathrm{bar}=1 \mathrm{~mm}) ; \mathrm{b})$ basidiospores $(\mathrm{bar}=10 \mu \mathrm{m}) ; \mathrm{c})$ cheilocystidia stained with congo red $(\mathrm{bar}=10 \mu \mathrm{m})$. 
Habitat and substrate: In Antarctic tundra on gametophytes of Saniona uncinata and Polytrichastrum alpinum (Hedw.) G.L. Smith (Bryophyta).

Examined material: Maritime Antarctica, South Shetland Archipelago, King George Island, Juan Carlos Point, S 62 ${ }^{\circ} 12^{\prime}$ 03.0" W 58 59' 43.8", 22-II-2008, leg. A. Casanova-Katny, det. E. Horak, CONC-F0349.

Distribution: Based on available data, endemic in maritime Antarctica (South Shetland Islands) and subantarctic islands (South Orkney, Signy) (Pegler et al. 1980, Putzke et al. 2012, this study).

Comments: This is to our knowledge only the second reported finding of basidiomata of this apparently rare species in its natural environment. Pegler et al (1980) who originally described it growing in vitro from a moss sample collected on Signy Island, suggested its specific association to Andreaea gainii Cardot. We confirm now S. uncinata and $P$. alpinum as alternative hosts which were not explicitly mentioned by Putzke et al. (2012) who reported fruiting bodies of $S$. antarctica for the first time in situ from the South Shetland archipelago.

Arrhenia antarctica (Singer) Redhead, Lutzoni, Moncalvo \& Vilgalys, Mycotaxon 83: 46 (2002)

Basionym: Omphalina antartica Singer, Beih. Sydowia 1: 16 (1957) [1956]

Systematic context: Tricholomataceae, Agaricales, Agaricomycotina, Basidiomycota.

Description: Basidiomata gregarious, pileate-stipitate, with pileus up to $30 \mathrm{~mm}$ in diam., plane-convex with depressed center or umbilicate, dark grey-brown, smooth, with a greasy shine when fresh (Fig. 5a); hymenium lamellate, lamellae thick, with blunt edge, decurrent, concolorous with the pileus or brighter colored, with darker edge (Fig. 5b); stem up to $30 \mathrm{~mm}$ long, central, concolorous with pileus; spores 5.7-7.2-8.6 $\times$ 4.3-4.8$5.7 \mu \mathrm{m},(\mathrm{Q} 1 / \mathrm{w}=1.3-1.7)$, ovoid to pip-shaped, hyaline, inamyloid (Fig. 5c); cystidia absent; hyphal septa with clamp-connections.

Habitat: In Antarctic tundra, mostly on and between cushions of $S$. uncinata (Bryophyta).

Examined material: Maritime Antarctica, South Shetland Archipelago, King George Island, Collins Bay, S 62 ${ }^{\circ} 0^{\prime}$ 08.7" W 58 51' 19.6", leg. A. Casanova-Katny, det. E. Horak, CONC-F0335; same location, 11-I-2009, leg. A. Casanova-Katny, det. G. Palfner, CONC-F0677; same location, 30-I-2012, leg. A. Casanova-Katny, det. E. Horak, CONC-F0803; Maritime Antarctica, South Shetland Archipelago, Robert Island, Coppermine Peninsula, Carlota Cove, S 62 $22^{\prime} 37.0^{\prime \prime} \mathrm{W}$ 59 42' 25.0", I-2009, leg. G. Torres-Mellado, det. G. Palfner, CONC-F0678; Maritime Antarctica, South Shetland Archipelago, Robert Island, Coppermine Peninsula, 15-01-2010, on D. antarctica, S $62^{\circ} 23^{\prime} 25.0^{\prime \prime} \mathrm{W} 59^{\circ} 41^{\prime}$ 06.0" (no collection); Maritime Antarctica, South Shetland Archipelago, Deception Island, Punta La Descubierta, 28-01-2019, on S. uncinata (no collection).

Distribution: Endemic in subantarctic zone and in maritime Antarctica (Guminska et al. 1994, Horak 1982, Pegler et al. 1980), probably the most frequently recorded Antarctic macromycete to date. 
G. PALFNER et al.

Comments: Apart from the most common moss host $S$. uncinata (Fig. 5), we could find Arrhenia antarctica also on Bryum sp., and, most notably, on the antarctic hairgrass D. antarctica (Fig. 6).
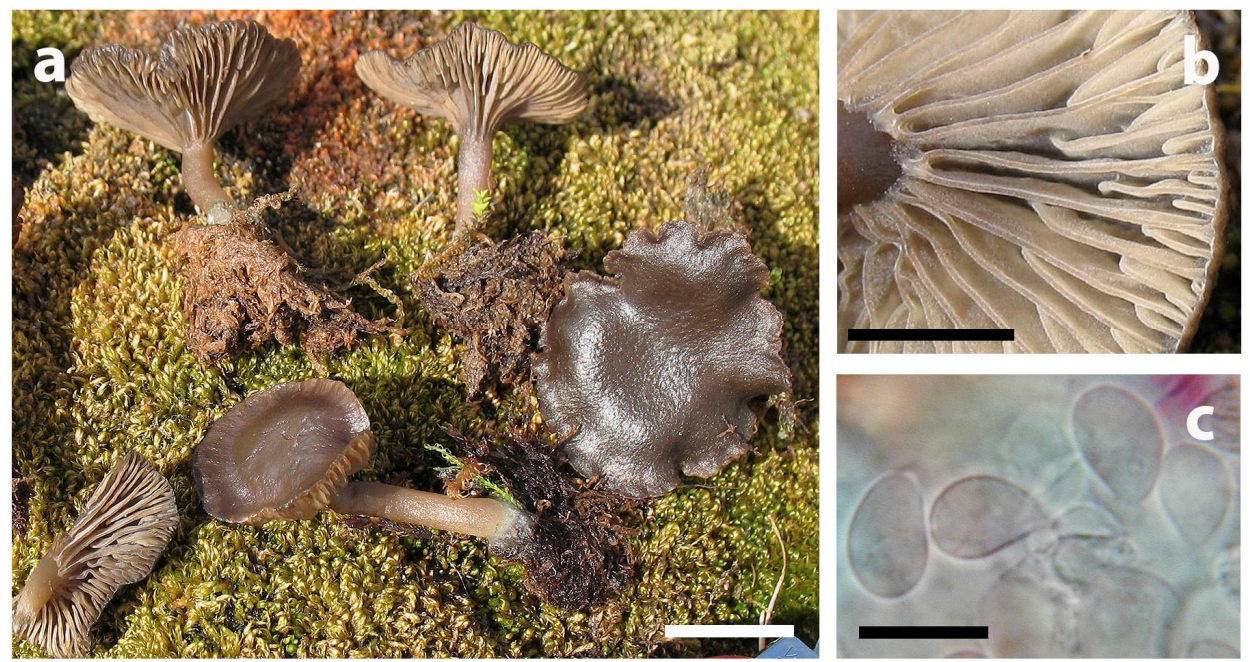

Fig. 5. Arrhenia antarctica (CONC-F0335) from Antarctica, King George Island; a) basidiomata in situ on Sanionia uncinata (bar $=10 \mathrm{~mm}$ ); b) enlarged view of hymenium (bar $=5 \mathrm{~mm}$ ); c) basidiospores $(\mathrm{bar}=10 \mu \mathrm{m})$.

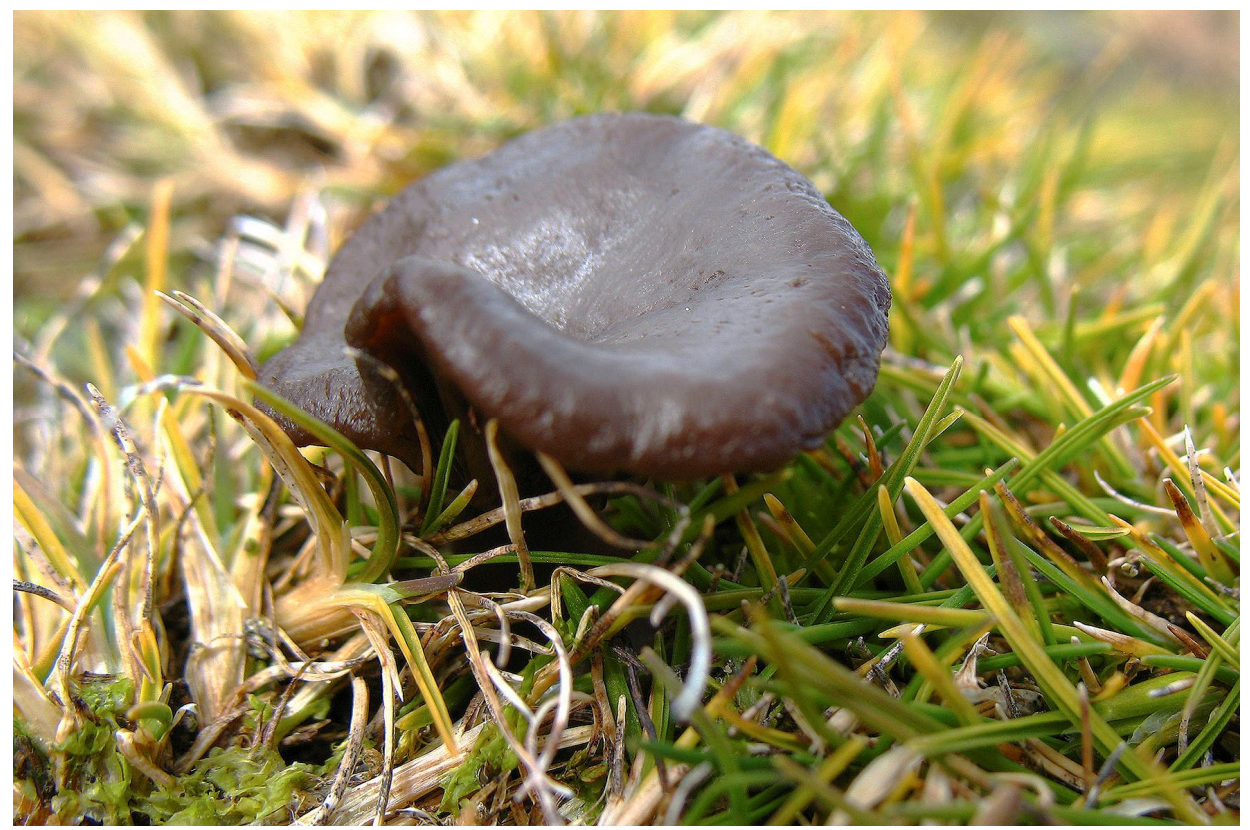

Fig. 6. Arrhenia antarctica on tussock of Deschampsia antarctica (antarctic hairgrass), Robert Island, South Shetland Archipelago, maritime Antarctica, 15 January 2010. 
Omphalina pyxidata (Bull.) Quél., Enchir. fung. (Paris): 43 (1886) Basionym: Agaricus pyxidatus Bull., Herb. Fr. (Paris) 12: tab. 568 (1792) Systematic context: Tricholomataceae, Agaricales, Agaricomycotina, Basidiomycota.

Description: Basidiomata gregarious, pileate-stipitate, with pileus up to $20 \mathrm{~mm}$ in diam., plane-convex with depressed center or funnel-shaped, margin often undulating, striate, reddish to pale brown, turning ochre brown when drying, smooth to finely scaly (Fig. 7a); hymenium lamellate, lamellae decurrent, whitish; stem up to $20 \mathrm{~mm}$ long, central, brighter colored than pileus; spores 6.4-7.4-7.9 $\times 5-5.3-5.7 \mu \mathrm{m},(\mathrm{Q} 1 / \mathrm{w}=1.3-1.6)$, ovoid to pip-shaped, hyaline, inamyloid (Fig. 7b); basidia tetrasporic; queilocystidia cylindrical, sometimes subcapitate, bent or with short outgrowths, approximately as long as basidia (Fig. 7c); hyphal septa with clamp-connections.
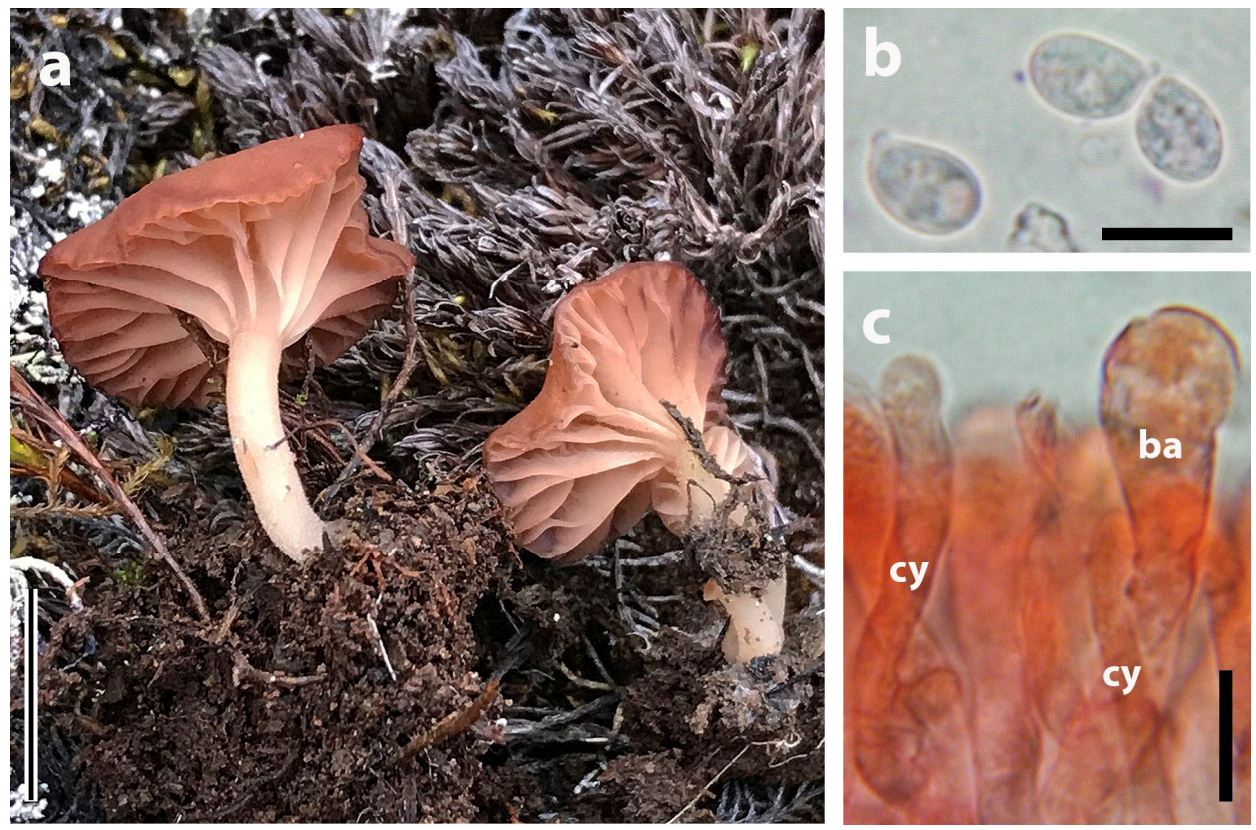

Fig. 7. Omphalina pyxidata (CONC-F2018) from Antarctica, King George Island; a) basidiomata in situ between mosses and lichens ( $\mathrm{bar}=10 \mathrm{~mm})$; b) basidiospores (bar $=10 \mu \mathrm{m})$; c) queilocystidia (cy) and basidium (ba) stained with congo red $(\mathrm{bar}=10 \mu \mathrm{m})$.

Habitat: In Antarctic tundra on and in between moss cushions and lichens.

Examined material: Maritime Antarctica, South Shetland Archipelago, King George Island, Plateau La Cruz, S $62^{\circ} 12^{\prime} 14.5^{\prime \prime}$ W 58 57' 36.1", 04-III-2020, on S. uncinata, leg. A. Casanova-Katny, det. G. Palfner, CONC-F2018; same location, same date, on Bryum sp., leg. A. Casanova-Katny, det. G. Palfner, CONC-F2019; Maritime Antarctica, South Shetland Archipelago, King George Island, Juan Carlos Point, S 62 ${ }^{\circ} 12^{\prime}$ 01.3" W 58 59' 45.9", 22-II-2008, leg. A. Casanova-Katny, det. G. Palfner, CONC-F0336; same location, 11-I-2009, leg. G. Gallegos, det. G. Palfner, CONC-F0679.

Distribution: Widely distributed in both hemispheres along a broad climatic gradient between subtropical and subpolar zones, graminophilous and bryophilous. 
Arrhenia cf. lilacinicolor (Bon) P.-A. Moreau \& Courtec., Docums Mycol. 34 (135-136): 48 (2008)

Basionym: Omphalia galericolor Romagn., Revue Mycol., Paris 17(1): 45 (1952)

Systematic context: Tricholomataceae, Agaricales, Agaricomycotina, Basidiomycota.

Description: Basidiomata gregarious, pileate-stipitate, with pileus up to $20 \mathrm{~mm}$ in diam., plane-convex with depressed center or funnel-shaped, pinkish brown, smooth (Fig. 8); hymenium lamellate, lamellae decurrent, whitish; stem up to $20 \mathrm{~mm}$ long, central, brighter colored than pileus (Fig. 8a); spores 6.4-6.8-7.2 $\times 5-5.9-6.4 \mu \mathrm{m},(\mathrm{Q} 1 / \mathrm{w}=1.1-$ 1.3), subglobose, hyaline, inamyloid (Fig. 8b); basidia tetrasporic; queilocystidia cylindrical, often bent, with thickenings or lateral outgrowths, longer than basidia and conspicuously protruding from the lamellar edge (Fig. 8c); hyphal septa with clampconnections.

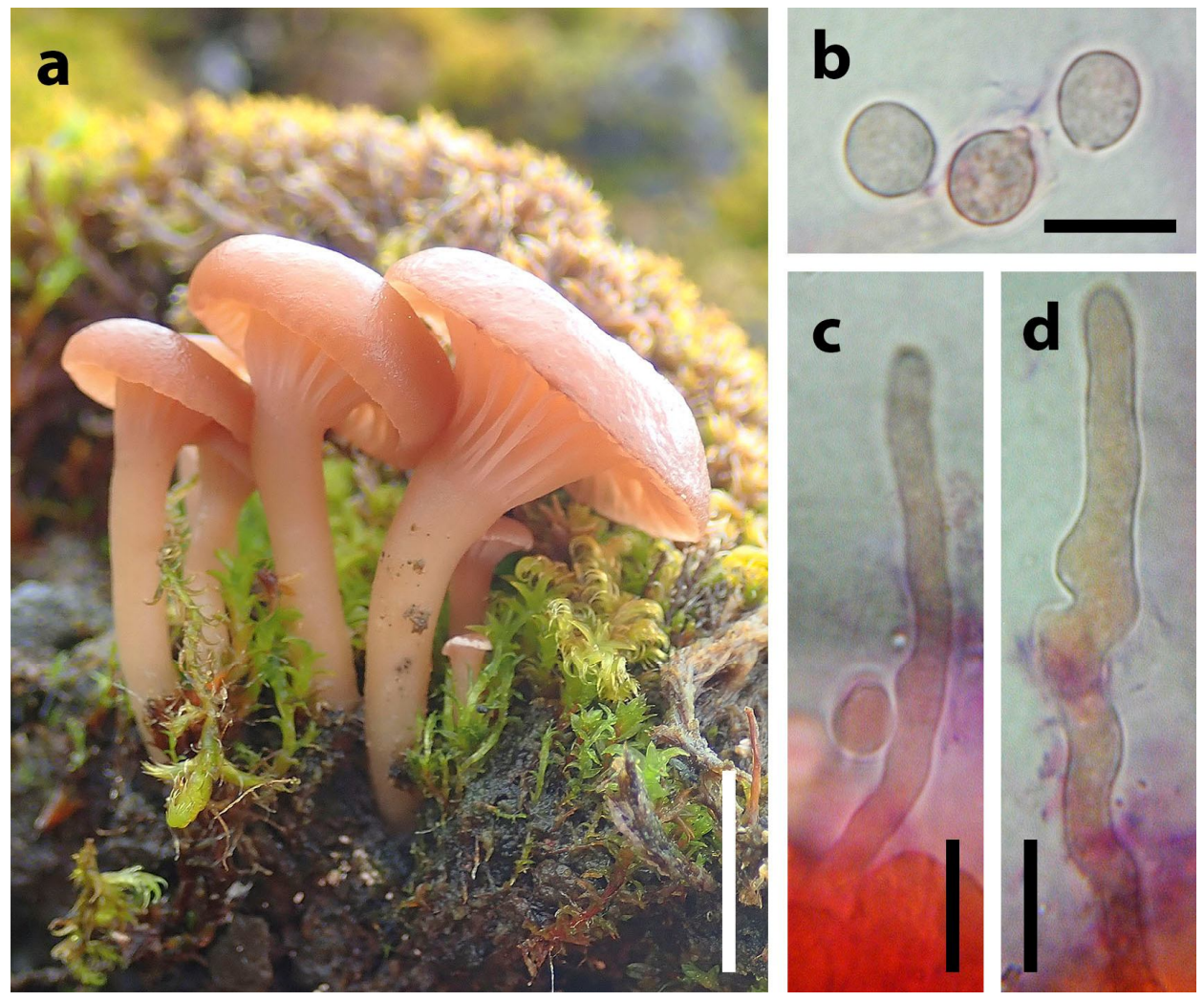

Fig. 8. Arrhenia $c f$. lilacinicolor (CONC-F2020) from Antarctica, King George Island; a) basidiomata in situ on Sanionia uncinata (bar $=10 \mathrm{~mm})$; b) basidiospores $(\mathrm{bar}=10 \mu \mathrm{m})$; c) and d) queilocystidia stained with congo red (bar: $10 \mu \mathrm{m}$ ).

Habitat: In Antarctic tundra on S. uncinata (Bryophyta).

Examined material: Maritime Antarctica, South Shetland Archipelago, King George Island, Collins Bay, S $62^{\circ} 10^{\prime}$ 09.2" W 58 51' 12.7", 04-III-2020, leg. A. CasanovaKatny, det. G. Palfner, CONC-F2020. 
Distribution: The taxonomic concept of Arrhenia lilacinicolor unites Omphalina galericolor and $O$. lilacinicolor Bon (1980: 91) which were previously considered separate species. The complex has so far mainly been reported from Mediterranean, temperate and boreal Europe, including arctic tundra habitats (Elborne 2012, Gminder and Krieglsteiner 2001).

Comments: A. lilacinicolor is similar to Omphalina pyxidata but distinguished by the more pinkish color of the pileus, subglobose spores and long, often irregularly shaped queilocystidia. Considering that previous findings are only from the Northern hemisphere (Europe) and that molecular data have not been obtained so far from our collection, we assign the name with the appropriate caution until further research is done.

Rickenella fibula (Bull.) Raithelh., Metrodiana 4: 67 (1973)

Basionym: Agaricus fibula Bull., Herb. Fr. (Paris) 4: tab. 186 (1784) [1783-84]

Systematic context: Repetobasidiaceae, Hymenochaetales, Agaricomycotina, Basidiomycota.

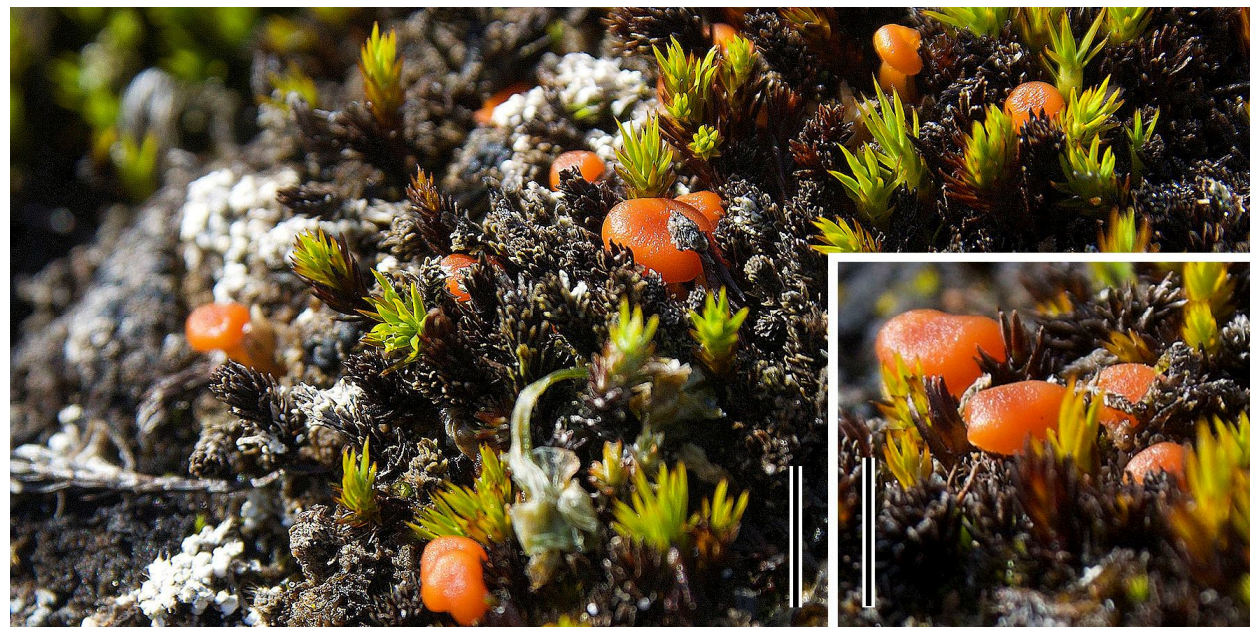

Fig. 9. Rickenella fibula (only photos, collection lost), Antarctica, Deception Island; young basidiomata in situ on Polytrichastrum alpinum; insert showing different group from the same spot (bar $=5 \mathrm{~mm}$ ).

Locality, habitat and substrate: Maritime Antarctica, South Shetland Archipelago, Deception Island, Crater Lake area, S 62 59' 16.9" W 60 39' 53.5", 22-I-2018, on Polytrichastrum alpinum growing on volcanic rock, leg. A. Casanova-Katny, det. G. Palfner, CONC-F2020.

Distribution: Widely distributed on both hemispheres, in subtropical, Mediterranean, boreal and polar zones, always associated to mosses; in Antarctica reported from South Sandwich Island, Bellingshausen Island, South Orkney Island and Signy Island (Pegler et al. 1980).

Comments: Unfortunately, the collection of these small but colorful mushrooms was lost, so we cannot provide a proper description. Nevertheless, we decided to include it, as the species has been reported previously from maritime Antarctica and can hardly be confused. It also represents our only record of a mushroom on Polytrichastrum alpinum from Deception Island. 


\section{Key for bryophilous macromycetes (Basidiomycota) recorded on South Shetland Archipelago, maritime Antarctica}

For previously recorded species which are not described in this study we include relevant references in parenthesis.

1 Basidioma regularly pileate-stipitate, pileus convex, plane-convex with central depression or funnel-shaped, hymenium distinctly lamellate, stipe more or less central.. 2 $1 *$ Basidioma with reduced, absent or excentric stipe, pileus cup-shaped, flabellate, conchate, spathulate or reniform, hymenium lamellate, with lamella-like folds or almost smooth

2 Lamellae not decurrent, spores brown, elliptic to amygdaliform, ampullate cheilocystidia present. Galerina

(for species see Guminska et al 1994 and Putzke and Pereira 1996)

2* Lamellae decurrent, spores hyaline, subglobose, ovoid or pip-shaped, cheilocystidia irregularly cylindrical, fusoid-lageniform or absent

3 Pileus of mature specimens usually less than $10 \mathrm{~mm}$ in diam., orange or greyish ochre4 3* Pileus of mature specimens usually more than $10 \mathrm{~mm}$ (up to 30 ) $\mathrm{mm}$ in diam., with brown, reddish brown or pinkish color....

4 In saline habitats close to the coastline, pileus pale grey ochre, hymenium with few anastomosing, lamella-like ridges, cystidia absent Arrhenia salina (Guminska et al. 1994) $4 *$ Not restricted to saline coastal habitats, pileus bright orange, lamellae well differentiated, with fusoid-lageniform hymenial cystidia Rickenella fibula

5 Pileus dark grey brown, fully mature specimens up to $30 \mathrm{~mm}$ in diam., disc with a greasy shine when fresh, spores ovoid to pip-shaped, cheilocystidia absent ....... Arrhenia antarctica

5* Pileus reddish brown, ochraceus brown or pinkish brown, mature specimens usually less than $20 \mathrm{~mm}$ in diam., disc opaque to finely scaly, cheilocystidia present.....

6 Pileus reddish brown to pale brown, smooth or finely scaly, spores ovoid to pipshaped, cheilocystidia cylindrical, usually not protruding from hymenium ..... Omphalina pyxidata

6* Pileus pinkish to pinkish brown, spores subglobose, cheilocystidia long, conspicuously protruding from hymenium, cylindrical or irregularly shaped .... Arrhenia cf. lilacinicolor

7 Basidioma up to $25 \mathrm{~mm}$ in diam., conchate or flabellate with undulating margin, stipe excentric, texture gelatinous, greyish brown, hymenium with lamella-like, forked ridges, spores pip-shaped, up to $11 \mu \mathrm{m}$ long. Leptoglossum lobatum (Horak 1980) 7* Basidoma very small, usually not exceeding $5 \mathrm{~mm}$ in diam., cup-shaped, flabellate, reniform or spathulate, astipitate or with reduced, excentric stipe, texture dry, hymenium lamellate or almost smooth with poorly pronounced ridges, spores subglobose, up to $8.5 \mu \mathrm{m}$ long.

8 Basidioma reniform to spathulate, brownish, hymenium lamellate, stipe short, excentric, spores brown, with suprahilar depression, cheilocystidia lageniform, capitate..

Simocybe antarctica

$8 *$ Basidioma cup-shaped, conchate or flabellate, astipitate, white, hymenium at maturity with poorly pronounced, ramified, lamella-like ridges, spores hyaline, without suprahilar depression, cystidia absent. Rimbachia bryophila 


\section{Discussion}

The Antarctic Peninsula is experiencing an unprecedented warming that is even twice as fast as in the rest of Antarctica (Bromwich et al. 2013), and has been measured for more than 50 years (Amesbury et al. 2017). This means that not only vascular plants may be able to increase their populations, as has been observed during the last 30-40 years (Parnikoza et al. 2009, Torres-Mellado et al. 2011), but that also the fungal communities will be more active in decomposition and nutrient cycling as well as in their role as parasites. Increasing temperature caused by global climate change is most pronounced in polar regions and has been generating visible and measurable effects in abiotic and biotic components of the respective ecosystems (Amesbury et al. 2017, Robinson et al. 2018). Although little is known about the impact of climate change on moss communities, it is estimated that there will be changes in their abundance, productivity and species composition. (He et al. 2016). Using simulated warming in in situ experiments, an increase in sporophyte generation in bryophyte communities of the South Shetland Archipelago has been reported (Casanova-Katny et al. 2016, Shortlidge et al. 2017), also there is evidence of change in sex ratios in moss gametophytes (Prather et al. 2019). Watching antarctic mosses beginning to override the historical geoclimatic restrictions of low temperatures on sexual reproduction, it could be expected that the associated mycobiota behaves in a similar way (Amesbury et al. 2017). This in turn could produce a negative feedback on the bryophyte community when associated fungal parasites are becoming more virulent. In fact, the observation of an increase of necrotic patches, particularly in the most frequent moss species $S$. uncinata, probably caused by various opportunistic fungal parasites (mainly belonging to Ascomycota and Mucoromycota), supports this assumption (Rosa et al. 2020).
Our record of Rimbachia bryophila adds a basidiomycete to this group of bryophilous and probably parasitic fungi. What remains uncertain is whether $R$. bryophila has arrived in Antarctica just recently or if it had been present earlier but rarely forming basidiomata, due to lower temperatures during the fruiting season. The same question arises with respect to Arrhenia cf. lilacinicolor, the second new addition to the list of antarctic higher fungi. Apart from those new records, we also provide evidence of increased reproductive activity of previously known antarctic fungi, expressed as records of basidiomata of at least two species on plant hosts which had not been mentioned earlier in relevant inventories (Guminska et al. 1994, Pegler et al. 1980). An interesting finding in this context is the record of Arrhenia antarctica, previously known only growing associated with bryophytes in the study area, on the antarctic hairgrass $D$. antarctica. We found also Simocybe antarctica on thalli of $S$. uncinata and Polytrichastrum alpinum, whereas Pegler et al. (1980) described the species only from Andreaea gainii, even suggesting a specific association between both species. Finally, we could add new locations to the known geographic range of some species of Antarctic fungi, with Rickenella fibula observed for the first time on Deception Island.

To date, the record of higher fungi from maritime Antarctica is still at the checklist level, with the count of additional taxa and locations going on, but we think that with our additional findings, critical mass may be sufficient to intend a provisional mycosociological analysis of mushroom-forming basidiomycete diversity in natural environments of the South Shetland Archipelago. The most frequently reported and most conspicuous taxa belonging to the Arrhenia-Omphalina complex all share common habitats and substrates, including those species which also grow outside Ant- 
arctica: O. pyxidata and A. lilacinicolor, like the regionally endemic $A$. antarctica, prefer open and low vegetation (grassland, heath, moss carpets), on mineral soil (weathering rock, sand, dunes), often with maritime influence and sometimes at sites exposed to periodical water stress (Gminder and Krieglsteiner 2001, Pegler et al. 1980, Singer 1956). It is still not totally clear whether these fungi are biotrophically associated to their host plants or just decomposers of dead remains: while they are typically cited as "bryophilous" (Redhead 1984), only very few studies have actually proven fungal structures like appresoria or haustoria backing a biotrophic relationship as in case of $R$. fibula (Kost 1988) which, however, is not closely related to Arrhenia and Omphalina according to DNA data (Redhead et al. 2002). Our finding of $A$. antarctica on grass tussocks which is coherent with Pegler et al. (1980) who cite the species from bog vegetation with presence of mosses and phanerogams on subantarctic South Georgia Island, suggests a lower level of bryophily than assumed for the genus (Redhead et al. 2002). Interestingly, a possible role as grass-root parasite has also been suggested for $O$. pyxidata by Hornby and Ward (1995).

Retreat of glaciers, one of the most conspicuous phenomena linked to global warming, affects local fungal diversity by offering new habitats (dos Santos et al. 2020). Recently, an in vitro culture study on the diversity of soil microfungi in a glacier retreat zone of the Collins Bay sector (dos Santos et al. 2020), has detected at least 19 genera, mainly belonging to the Phyla Ascomycota and Mortierellomycota but only a minor proportion of basidiomycetes, none of which is related with the taxa of our study. Jumpponen et al. (2012) suggest propagule input of plants and fungi together with presence of microsites with favourable soil structure and/or microclimate as main drivers of succession of plant-fungal communities on a retreating glacier forefront of the Rocky Mountains although they emphasize that more research is necessary, especially for better understanding of fungal succession. In this context, a question arises if warming favors establishment of widely distributed, more broadly adapted fungi before native or endemic, cold-adapted species. The data of dos Santos et al. (2020) seem to support this view and coincide with our findings of $R$. bryophila and A. lilacinicolor, although it must be emphasized that Antarctic vegetation and mycobiota in general present a very low level of endemism.

Finally, we are aware that our data are still too few to allow general conclusions about tendencies in the development of macrofungal communities in Antarctica. Foraying has only been sporadic at several sites and the local sampling effort markedly affects the number of records, as can be seen in case of Fildes Peninsula, the site with most fungal records, which is where moss studies have been mainly developed (Casanova-Katny and Cavieres 2012, Casanova-Katny et al. 2016). There is still much to learn about diversity and succession in the increasing ice-free areas: Under the strongest forcing scenario, an estimated $25 \%$ expansion due to climate warming in the Antarctic Peninsula has been forecast (Lee et al. 2017). Concomitantly, for the next century, a homogenization of Antarctic terrestrial diversity has been predicted, accompanied by increased entry of invasive species and a simultaneous decline of Antarctic endemic species which might not be able to adapt in such a short period (Duffy and Lee 2019).

\section{References}

Andreyev, M. P. (1989): The lichens in the vicinity of Bellingshausen station, King George Island. Polar Geography and Geology, 13: 42-45. 
Amesbury, M. J., Roland, T. P., Royles, J., Hodgson, D. A., Convey, P., Griffiths, H. and Charman, D. J. (2017): Widespread biological response to rapid warming on the Antarctic Peninsula. Current Biology, 27(11): 1616-1622.

Bromwich, D. H., Nicolas, J. P., Monaghan, A. J., Lazzara, M. A., Keller, L. M., Weidner, G. A. and WiLson, A. B. (2012): Central West Antarctica among the most rapidly warming regions on Earth. Nature Geoscience, 6(2): 139-145.

Carrasco, J., Gonzalez, M. (2007): Climatología de la Peninsula Antártica y de la base Presidente Eduardo Frei Montalva. Dirección General de Aeronáutica Civil. Dirección Meteorológica de Chile. (http://164.77.222.61/climatologia/publicaciones/Climatologia_Frei.pdf).

Casanova-Katny, M. A and Cavieres, L. A. (2012): Antarctic moss carpets facilitate growth of Deschampsia antarctica but not its survival. Polar Biology, 35(12): 1869-1878.

Casanova-Katny, M. A., Torres-Mellado, G. A. and Eppley, S. M. (2016): Reproductive output of mosses under experimental warming on Fildes Peninsula, King George Island, maritime Antarctica. Revista Chilena De Historia Natural, 89: 1-9.

dos Santos, J. A., Meyer, A., and Sette L.D. (2020): Fungal Community in Antarctic Soil Along the Retreating Collins Glacier (Fildes Peninsula, King George Island). Microorganisms, 8: 15.

DufFY, G. A., LeE J. R. (2019): Ice-free area expansion compounds the non-native species threat to Antarctic terrestrial biodiversity. Biological Conservation, 232: 253-257.

DiBAn, M. J. (2019): Patrones biogeográficos de los ensambles de hongos Agaricales s.l. en bosques dominados por Nothofagus obliqua (Mirb) Oerst. y Nothofagus macrocarpa (A.Dc.) Vasq. \& Rodr. en un gradiente latitudinal. PhD thesis, Universidad de Chile, http://repositorio. uchile.cl/ (accessed 21 november 2020)

Elborne, S.A. (2012): Omphalina Quél. In: H. Knudsen \& J. Vesterholt (eds.): Funga Nordica, Vol. 1. Nordsvamp, Copenhague, Denmark, $511 \mathrm{p}$.

Gminder, A., Krieglsteiner, G. (2001): Tricholomataceae. In: G. Krieglsteiner (ed.): Die Grosspilze Baden-Württembergs, Vol. 3. Editorial Ulmer, Stuttgart, Germany, 634 p.

GonZÁlez, I., HeBel, I. and JAÑA, R. (2019): Distribución potencial de Sanionia spp.en dos momentos del Holoceno en península Fildes isla Rey Jorge Antártica. Anales Instituto Patagonia (Chile), 47: 7-17.

Guminska, B., HeinRich, Z. and Olech, M. (1994): Macromycetes of the South Shetland Islands (Antarctica). Polish Polar Research, 15: 103-109.

Hausknecht, A., KlofaC, W. (2011): Ergebnisse des Mykologischen Arbeitstreffens in Johnsbach (Nationalpark Gesäuse, Steiermark) im August 2010. Österreichische Zeitschrift für Pilzkunde, 20: 103-119.

HE, X., HE, K.S., HYvöNEN, J. (2016) Will bryophytes survive in a warming world? Perspectives in Plant Ecology, Evolution and Systematics, 19: 49-60.

HoRAK, E. (1980): Agaricales y gasteromicetes secotioides. In: S. A. Guarrera, I. J. Gamundí de Amos, C. M. Matteri (eds.): Flora Criptogámica de Tierra del Fuego, tomo XI, fascículo 6: Fungi, Basidiomycetes, FECYC, Buenos Aires, 524 p.

HORAK, E. (1982): Agaricales in Antarctica and Subantarctica: Distribution, Ecology and Taxonomy. In: G. A. Laursen, J. F. Ammirati (eds): Arctic and Alpine Mycology, Vol. 1, University of Washington Press, Seattle, pp. 82-118

Høiland, K. (1976): The genera Leptoglossum, Arrhenia, Phaeotellus, and Cyphellostereum in Norway and Svalbard. Norwegian Journal of Botany, 23: 201-212.

HORNBY, D., WARD, E. (1995) Wanted: Omphalina pyxidata. Mycologist, 9(1): 36.

Jumpronen, A., Brown, S.P., Q., Trappe, J.M., Cazares, E. and Strömmer, R. (2012): Twenty years of research on fungal-plant interactions on Lyman Glacier forefront - lessons learned and questions yet unanswered. Fungal Ecology, 5: 430-442.

Kaya, A., Akata, I. and Uzun, Y. (2013): Two new records for Turkish Agaricales. Biological Diversity and Conservation, 6(3): 150-152.

Kost, G. (1988) Interactions between Basidiomycetes amd Bryophyta. Endocytobiosis and Cell Research, 5: 287-308.

Lee, J. R., Raymond, B., Bracegirdle, T. J., Chades, I., Fuller, R. A., Shaw, J. D. and Terauds, A. (2017): Climate change drives expansion of Antarctic ice-free habitat. 
Nature, 547(7661): 49-54. https://doi.org/10.1038/nature22996

LæSSØE, T. (2012): Rimbachia Pat. In: H. Knudsen \& J. Vesterholt (eds.): Funga Nordica, Vol. 1. Nordsvamp, Copenhague, Denmark, 511 p.

Ochyra, R., Smith, R. and Bednarek-Ochyra, H. (2008): The illustrated moss flora of Antarctica. Cambridge: Cambridge University Press, 723 p.

Parnikoza, I., Convey, P., Dykyy, I., Trokhymets, V., Milinevsky, G., Tyschenko, O., Inozemtseva, D. and Kozeretska, I. (2009): Current status of the Antarctic herb tundra formation in the Central Argentine Islands. Global Change Biology, 15(7): 1685-1693.

Pegler, D. N., Spooner, B. M. and Smith, R. I. L. (1980): Higher Fungi of Antarctica, the Subantarctic Zone and Falkland Islands. Kew Bulletin, 35(3): 499-562.

Prather, H. M., Casanova-Katny, M. A., Clements, A. F., Chmielewski, M. W., Balkan, M. A., Shortlidge, Rosenstiel, T.N. and Eppley, S. M. (2019): Species-specific effects of passive warming in an Antarctic moss system. Royal Society Open Science, 6(11): 1-13.

Putzke, J., PereirA, A. B. (1996): Macroscopic fungi from the South Shetland Islands, Antarctica. Serie Cientifica INACH, 46: 31-39.

Putzke, J., Putzke, M. T. L., Pereira, A. B. and Albuquerque, M. P. (2012): Agaricales (Basidiomycota) fungi in the South Shetland Islands, Antarctica. INCT-APA Annual Activity Report, 71-74. http://dx.doi.org/10.4322/apa.2014.065

REDHEAD, S. A. (1984): Arrhenia and Rimbachia, expanded generic concepts, and a reevaluation of Leptoglossum with emphasis on muscicolous North American taxa. Canadian Journal of Botany, 62: 865-892.

REDHEAD, S. A. (1997): Macrofungi of British Columbia: requirements for inventory, Vol. 28, British Columbia, Ministry of Forests Research Program, $119 \mathrm{p}$.

Redhead, S. A., Lutzoni, F., Moncalvo, J. M. and Vilgalys, R. (2002): Phylogeny of Agarics: Partial systematics solutions for core omphalinoid genera in the Agaricales (Euagarics). Mycotaxon, 83: 19-57.

Robinson, S. A., King, D. H., Bramley-Alves, J., Waterman, M. J., Ashcroft, M. B., Wasley, J., Turnbull, J. D., Miller, R.E., Ryan-Colton, E., Benny, T., Mullany, K., Clarke, L., BARRY, L. and HUA, Q. (2018): Rapid change in East Antarctic terrestrial vegetation in response to regional drying. Nature Climate Change, 8(10): 879-884.

Rosa, L. H., De Sousa, J. R. P., De Menezes, G. C. A., Coelho, L. D., Carvalho-Silvan, M., Convey, P. and Camara, P. (2020): Opportunistic fungi found in fairy rings are present on different moss species in the Antarctic Peninsula. Polar Biology, 43(5): 587-596.

SenN-Irlet, B., Moreau, P.A. (2003): Notes on three Rimbachia species from the Alps. Czech Mycology, 54: 145-154.

SEGEDIN, B. P. (1994): Studies in the Agaricales of New Zealand: New records and new species of the genera Cheimonophyllum, Mniopetalum, and Anthracophyllum (Tricholomataceae, Collybieae). New Zealand Journal of Botany, 32(1): 61-72. doi:10.1080/0028825x.1994.10410407

Shortlidge, E. E., Eppley, S. M., Kohler, H., Rosenstiel, T. N., Zuniga, G. E. and CasanovaKATNY, M. A. (2017): Passive warming reduces stress and shifts reproductive effort in the Antarctic moss, Polytrichastrum alpinum. Annals of Botany, 119(1): 27-38.

Singer, R. (1956): A fungus collected in the Antarctic. Sydowia-Beihefte I, 16-23.

Svane, S. J., AlstruP, V. (2004): Some lichenicolous fungi from Iceland. Acta Botanica Islandica, 14: 53-58.

Torres-Mellado, G. A., JaÑa, R. and Casanova-Katny, M. A. (2011): Antarctic hairgrass expansion in the South Shetland archipelago and Antarctic Peninsula revisited. Polar Biology, 34(11): 1679-1688.

Vizzini, A., CurTi, M., Contu, M. and ERCole, E. (2012): A new cystidiate variety of Omphalina pyxidata (Basidiomycota, tricholomatoid clade) from Italy. Mycotaxon, 120: 361-371.

\section{Web sources / Other sources}

[1] Index Fungorum (http://www.indexfungorum.org/) 